\title{
Unique molecular distortion in the 2,4,6-tri-t-butylphenyl group
}

\author{
Shigekazu Ito, ${ }^{{ }^{a}}$ Hideaki Miyake, ${ }^{b}$ and Masaaki Yoshifuji ${ }^{c}$ \\ ${ }^{a}$ Department of Applied Chemistry, Graduate School of Science and Engineering, Tokyo Institute \\ of Technology, 2-12-1 Ookayama, Meguro, Tokyo 152-8552, Japan \\ ${ }^{b}$ Department of Chemistry, Graduate School of Science, Tohoku University, Aoba, Sendai \\ 980-8578, Japan \\ ${ }^{c}$ Department of Chemistry, The University of Alabama, Tuscaloosa 35487-0336, USA \\ E-mail: ito.s.ao@m.titech.ac.jp
}

This article is dedicated to Professor Anthony J. Arduengo, III on the occasion of his 60th birthday

\begin{abstract}
X-ray structure of a stable chlorophosphine and a secondary phosphine both bearing one or more sterically bulky 2,4,6-tri-t-butylphenyl (Mes*) group(s) are discussed in terms of molecular distortion. Steric encumbrance of the bulky aromatic ring induces a boat-type structure of the six-membered aromatic ring, and the degree of distortion depends on a substituent in the ipso position.
\end{abstract}

Keywords: Molecular distortion, steric effect, conformation, X-ray structure

\section{Introduction}

Kinetic stabilization techniques with sterically encumbered substituents have been utilized for isolation of inherently unstable chemical species including multiple bonds of heavier main group elements. Since successful characterization of a stable $\mathrm{P}=\mathrm{P}$ double bond, named as diphosphene, a number of congeners of alkenes and alkynes have been synthesized by use of steric protecting 
groups. The following Scheme 1 shows formula of the first isolable diphosphene reported in 1981 bearing 2,4,6-tri-t-butylphenyl groups (1). ${ }^{1}$ This bulky aryl group, hereafter abbreviated as Mes*, has played an important role in development of main group chemistry for connecting various $\pi$-conjugated systems. Indeed a number of low-coordinated organophosphorus compounds bearing the Mes* group(s) have been synthesized and characterized. ${ }^{2,3}$

On the other hand, we have found that several normal organic compounds bearing the Mes* group(s) show remarkable molecular distortion of the aromatic skeleton. We reported that an extremely crowded phosphinic chloride $\mathbf{2}^{4}$ exhibits boat-shaped aromatic rings according to its X-ray structure. ${ }^{5,6}$ Also we found a similar distortion of the aromatic ring in $\mathbf{3}^{7}$ and tri(carbonyl)chromium $\pi$-complexes of diphosphene $1 .^{8}$

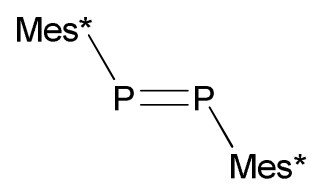

1

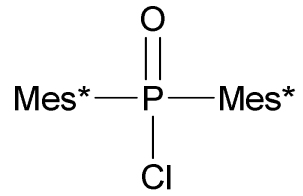

2

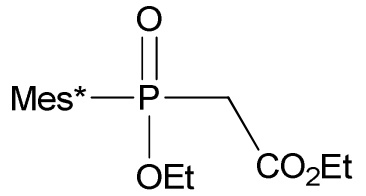

3

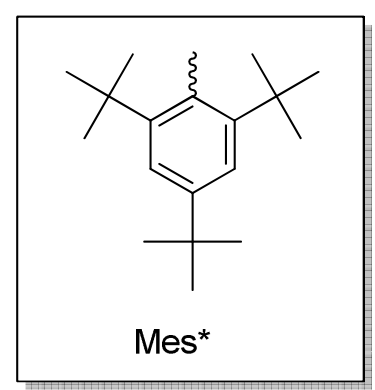

In this paper we discuss two typical structural characteristics of normal $\lambda^{3} \sigma^{3}$-phosphines bearing the Mes* group(s). An air-tolerant tertiary chlorophosphine exhibits remarkable distortion of the aromatic ring as well as sterically congested conformation. A secondary ethynylphosphine bearing two Mes* groups shows high stability in air and the structure in the solid state is discussed.

\section{Results and Discussion}

\section{Air-stable chlorophosphine bearing the Mes* group}

Whereas chlorophosphines are normally decomposed in air, (3-t-butylcyclopenta-2,4-dienyl)chloro(2,4,6-tri-t-butylphenyl)phosphine (4) can be handled in the ordinary atmosphere and recrystallized from dichloromethane, and the structural properties were discussed in our previous report. ${ }^{9}$ Figure 1 shows a representation of the molecular structure of $\mathbf{4}$ $[(R, S)$-isomer]. The $\mathrm{PCl}$ moiety is effectively protected by the steric encumbrance of the Mes* 
sphere to reduce reactivity of the phosphorus center. On the other hand, steric hindrance around the phosphorus atom causes remarkable distortion of the aromatic 6-membered ring to a boat-type conformation $\left[\Theta\left(\mathrm{P}-\mathrm{C}_{i p s o}-\mathrm{C}_{\text {ortho }}-\mathrm{C}_{t \mathrm{Bu}}\right)=-56.07,44.09^{\circ} . \Theta\left(\mathrm{P}-\mathrm{C}_{i p s o}-\mathrm{C}_{\text {ortho }}-\mathrm{C}_{\text {meta }}\right)=\right.$ 130.97, $\left.-109.28^{\circ} . \Theta\left(\mathrm{C}_{\text {ipso }}-\mathrm{C}_{\text {ortho }}-\mathrm{C}_{\text {meta }}-\mathrm{C}_{\text {para }}\right)\right]=-4.35,4.20^{\circ}$, and correspondingly the ipso carbon atom in the Mes* group exhibits slight pyramidalization $\left[\Sigma\right.$ (angles) $=354.1^{\circ}$ ], where $\mathrm{C}_{t \mathrm{Bu}}$ stands for the base carbon of the $t$-butyl group attached to $\mathrm{C}_{\text {ortho }}$. As for the conformational characteristics of $\mathbf{4}$, despite the considerable steric repulsion, the $t$-butyl group on the cyclopentadienyl ring is not far from the Mes* moiety. Molecular mechanics calculations of the most stable conformer for the $(R, S)$ isomer suggests an optimum structure with the dihedral angle of $120^{\circ}$ around the $\mathrm{P}-\mathrm{C} 1$ bond [ $\left.\Theta\left(\mathrm{C}_{i p s o}-\mathrm{P}-\mathrm{C} 1-\mathrm{C} 2\right)\right]$. This sterically congested form of $\mathbf{4}$ might be affected by the $\mathrm{CH}-\pi$ interaction between the Mes* and cyclopentadienyl groups ${ }^{10}$ which might also be suggested from the higher field chemical shifts of the proton on the $\mathrm{C} 2$ position $\left(\delta_{\mathrm{H}}=\right.$ $4.47 \mathrm{ppm}$ ) compared with those on the $\mathrm{C} 4$ and $\mathrm{C} 5$ positions (6.43 and $6.27 \mathrm{ppm})$. Additionally, the $\mathrm{P}-\mathrm{C}_{i p s o}-\mathrm{C}_{\text {ortho }}$ angles of 128.6(2) and 107.2(2) ${ }^{\circ}$ indicate the conformational property of the $\mathrm{P}(\mathrm{Cl})\left(\mathrm{C}_{5} \mathrm{H}_{4} t \mathrm{Bu}\right)$ moiety to induce different steric effects of the $o-t \mathrm{Bu}$ groups, as observed also in $2^{6}$ and a sterically crowded dichlorophosphine $\mathrm{Mes}^{*} \mathrm{PCl}_{2}{ }^{9}$

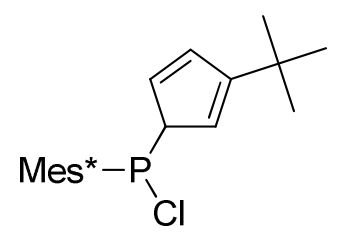

4

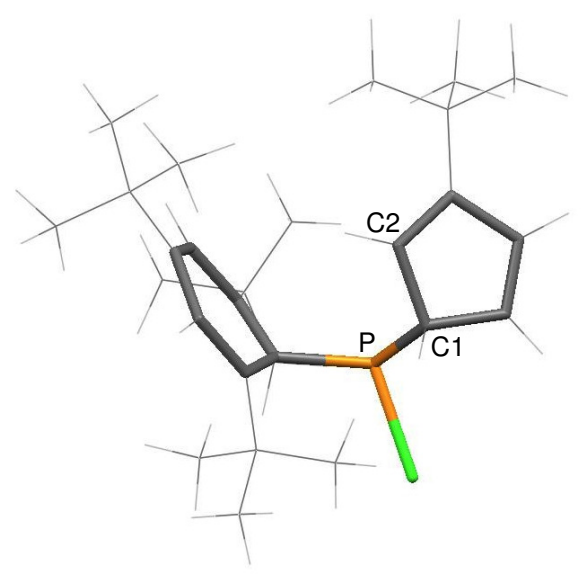

Figure 1. Molecular structure of $4 .^{9}$ 


\section{Characterization of a stable secondary ethynylphosphine}

Phosphines bearing both $\mathrm{P}-\mathrm{H}$ bond and acetylene structure are of interest from the views of synthesis of particular organophosphorus compounds as well as coordination chemistry. For example, we have utilized some (2,4,6-tri-t-butylphenyl)(ethynyl)phosphines for preparation of the corresponding 3,4-diphosphinidenecyclobutenes (DPCB) which have recently been studied in terms of unique and efficient catalysts. ${ }^{11}$ However, there has not been a detailed discussion of characteristics of the secondary ethynylphosphines so far. Previously, we reported unique trimerization reaction of a sterically encumbered phosphanylidene carbenoid $[\mathrm{Mes} * \mathrm{P}=\mathrm{C}(\mathrm{Br}) \mathrm{Li}]^{3 \mathrm{a}}$ affording the corresponding 1,3,6-triphosphafulvene. ${ }^{12}$ At the same time, we observed formation of a secondary ethynylphosphine $\mathbf{5}$ as one of the byproducts. We succeeded in isolation, crystallization, and X-ray structural analysis of $\mathbf{5}$.

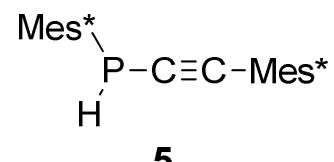

Figure 2a displays an ORTEP drawing of 5 (50\% probability ellipsoids). The aromatic ring in the Mes*P moiety shows smaller distortion compared with $4\left[\Theta\left(\mathrm{P}-\mathrm{C}_{i p s o}-\mathrm{C}_{\text {ortho }}-\mathrm{C}_{t \mathrm{Bu}}\right)=26.49\right.$, $-24.94^{\circ}$.a $\left.\Theta\left(\mathrm{P}-\mathrm{C}_{i p s o}-\mathrm{C}_{\text {ortho }}-\mathrm{C}_{\text {meta }}\right)=159.10,-159.18^{\circ} . \Theta\left(\mathrm{C}_{\text {ipso }}-\mathrm{C}_{\text {ortho }}-\mathrm{C}_{\text {meta }}-\mathrm{C}_{\text {para }}\right)\right]=-1.37$, $0.90^{\circ}$, and smaller pyramidalization of the $\mathrm{C}_{\mathrm{ipso}}$ atom $\left[\Sigma(\right.$ angles $\left.)=358.8^{\circ}\right]$. This boat-like structure, though indicating somewhat of an envelope-type distortion, is comparable to the aryl groups in 1. ${ }^{1}$ On the other hand, the six-membered ring in the Mes*C group shows almost planar structure $\left[\Theta\left(C 2-\mathrm{C}_{i p s o}-\mathrm{C}_{\text {ortho }}-\mathrm{C}_{t \mathrm{Bu}}\right)=3.75,-2.55^{\circ} . \Theta\left(\mathrm{P}-\mathrm{C}_{i p s o}-\mathrm{C}_{\text {ortho }}-\mathrm{C}_{\text {meta }}\right)=175.98,-175.06^{\circ}\right.$. $\left.\Theta\left(\mathrm{C}_{\text {ipso }}-\mathrm{C}_{\text {ortho }}-\mathrm{C}_{\text {meta }}-\mathrm{C}_{\text {para }}\right)\right]=0.80,1.15^{\circ}$. Thus, the distortion of aromatic rings depend on steric encumbrance around the ipso carbon atom of the Mes* group. The P1-C1 and $\mathrm{C} 1-\mathrm{C} 2$ distances and the $\mathrm{P} 1-\mathrm{C} 1-\mathrm{C} 2$ angle are comparable to ethynylphosphine $(\mathbf{6})\left[\mathrm{H}_{2} \mathrm{PC} \equiv \mathrm{CH}\right](\mathrm{P}-\mathrm{C} 1.774 \AA$, $\mathrm{C} \equiv \mathrm{C} 1.208 \AA$ A, $\left.\mathrm{P}-\mathrm{C} \equiv \mathrm{C} 173^{\circ}\right) .{ }^{13}$ The Mes ${ }^{*} \mathrm{C} \equiv \mathrm{C}$ moiety shows similar geometrical parameters to 7. ${ }^{14}$ Crystal structure of 5 (Figure $2 b$ ) indicates effective steric encumbrance around the inherently unstable $\mathrm{PH}-\mathrm{C} \equiv \mathrm{C}$ moiety to prevent interaction by small molecules.

As discussed above, the magnitude of the benzene ring distortion of $\mathbf{5}$ depends on steric encumbrance around the ipso substituent. Similarly to 5, highly stabilized 1,3-diphosphacyclobutane-2,4-diyls 8 and $\mathbf{9}$ also exhibit the ring distortion, and the distortion 
parameters around the Mes* groups depend on the substituents at the phosphorus atoms. The average torsion angles $\Theta\left(\mathrm{C}_{\text {skeletal }}-\mathrm{C}_{i p s o}-\mathrm{C}_{\text {ortho }}-\mathrm{C}_{t \mathrm{Bu}}\right)$ and $\Theta\left(\mathrm{C}_{\text {skeletal }}-\mathrm{C}_{i p s o}-\mathrm{C}_{\text {ortho }}-\mathrm{C}_{\text {meta }}\right)$ for $\mathbf{8}$ are $26.10^{\circ}$ and $155.84^{\circ},{ }^{15}$ respectively, whereas 9 shows smaller degree of distortion $\left[\Theta\left(\mathrm{C}_{\text {skeletal }}-\mathrm{C}_{\text {ipso }}-\mathrm{C}_{\text {ortho }}-\mathrm{C}_{t \mathrm{Bu}}\right)=15.5^{\circ}, 9.5^{\circ} . \Theta\left(\mathrm{C}_{\text {skeletal }}-\mathrm{C}_{\text {ipso }}-\mathrm{C}_{\text {ortho }}-\mathrm{C}_{\text {meta }}\right)=163.7^{\circ}, 173.5^{\circ}\right] .^{16}$ Also, the magnitude of the benzene distortion might be responsible for the air-stability; 8 did not change under air, whereas 9 decomposed completely under ambient conditions within a day. The distortion of the Mes* group appears to be crucial for stabilizing unstable molecular structure.

a)

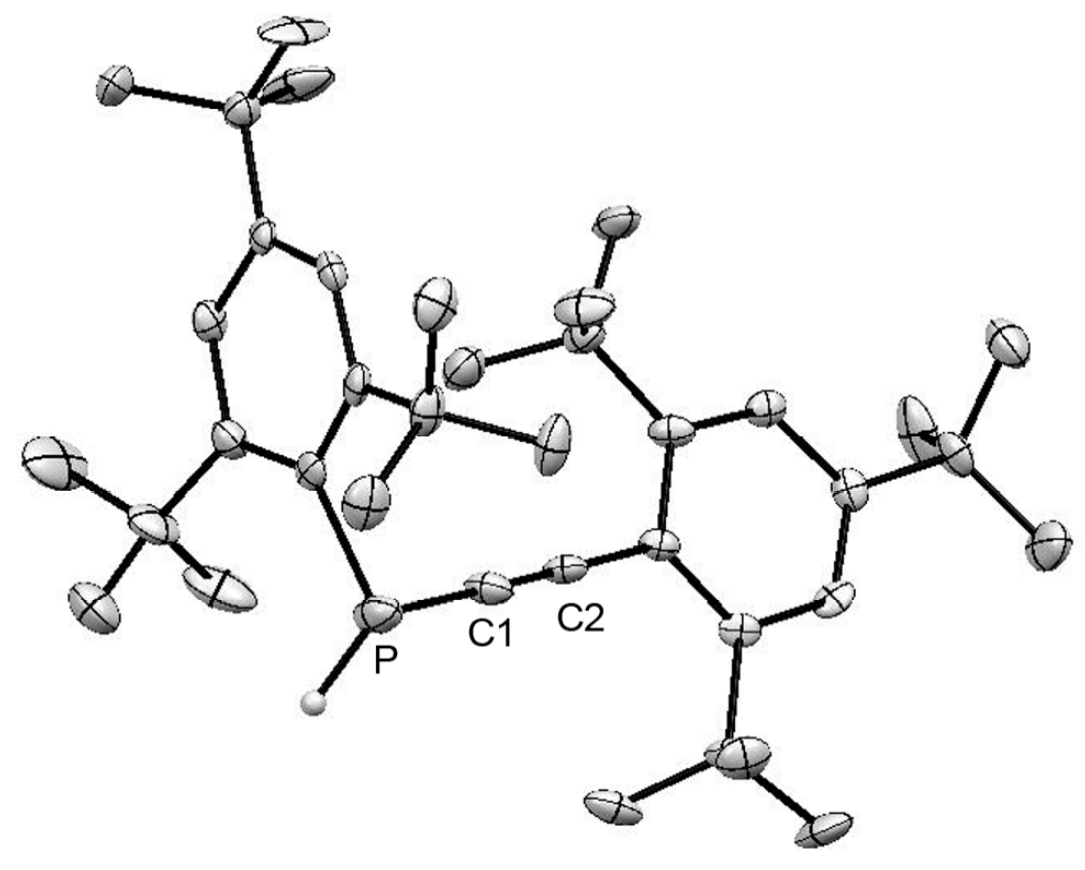


b)

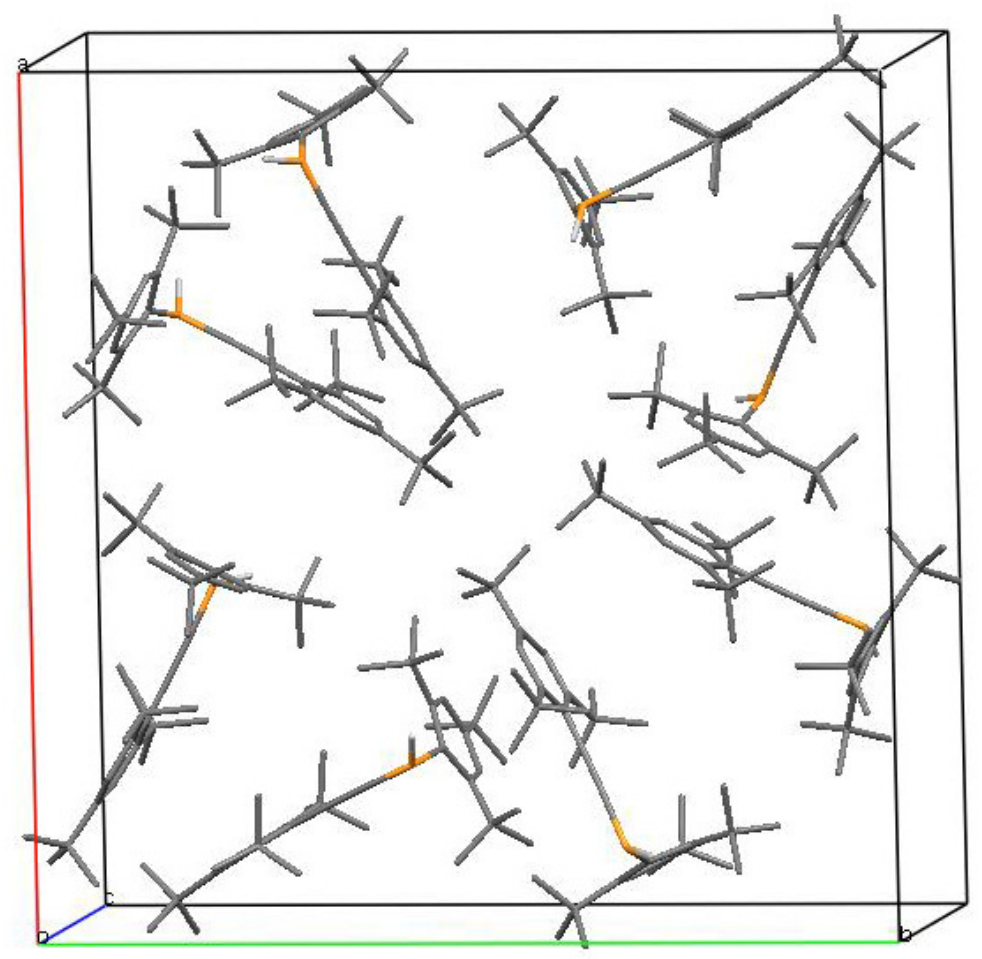

Figure 2. a) molecular structure of 5 (50\% probability ellipsoids). The $p$-t-butyl group of Mes* at $\mathrm{P}$ is disordered, and the atoms with predominant occupancy factor (0.84) are displayed. Hydrogen atoms except for one attached to the phosphorus atom are omitted for clarity. Selected bond lengths $(\AA)$ and angles $\left({ }^{\circ}\right)$ : $\mathrm{P}-\mathrm{C} 1$ 1.770(5), $\mathrm{P}-\mathrm{C}_{\mathrm{Mes}^{*}}$ 1.855(4), C1-C2 1.190(7), C2-C $\mathrm{C}_{\text {Mes* }}$ 1.456(7). C1-P-C $\mathrm{Mes}^{*}$ 99.8(2), P-C1-C2 178.3(4), C1-C2- $\mathrm{C}_{\mathrm{Mes}^{*}}$ 179.0(5). b) Crystal structure of 5 along the $c$ axis.
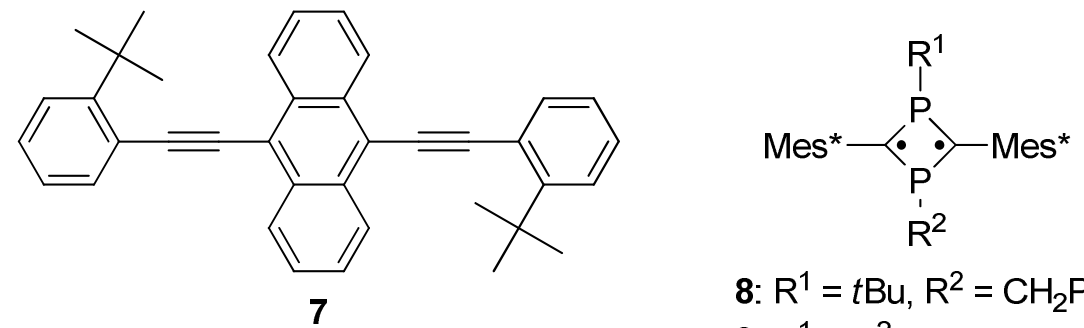

8: $\mathrm{R}^{1}=t \mathrm{Bu}, \mathrm{R}^{2}=\mathrm{CH}_{2} \mathrm{Ph}$

9: $R^{1}=R^{2}=M e$ 


\section{Comparison of the aromatic $\mathrm{C}-\mathrm{C}$ distances of (4 and 5)}

As demonstrated in the research on cyclophanes, distortion of benzene ring causes alteration of the aromatic $\mathrm{C}-\mathrm{C}$ bond distances. ${ }^{17,18}$ Thus, similar phenomenon is plausible in the cases of 4 and 5. Table 1 displays the aromatic $\mathrm{C}-\mathrm{C}$ distances of $\mathbf{4}$ and $\mathbf{5}$.

Due to the steric repulsion between the Mes* group and the ipso-substituents, parameters $d_{1}$ of both 4 and 5 exhibit remarkable elongation from the normal $\mathrm{C}-\mathrm{C}$ distance of benzene (1.394 $\AA$ ). This finding indicates that the elongated $\mathrm{C}-\mathrm{C}$ distances do not necessarily correspond to the distorted aromatic ring because the elongation is observed even in the almost planar Mes*C moiety of 5. On the other hand, $d_{2}$ and $d_{3}$ are close to the normal aromatic $\mathrm{C}-\mathrm{C}$ bond, indicating smaller steric encumbrance in comparison with those around the ipso position, and the intrinsic aromatic stabilizing tendency.

Table 1. $\mathrm{C}-\mathrm{C}$ Bond distances of the aromatic rings in $\mathbf{4}$ and $\mathbf{5}$

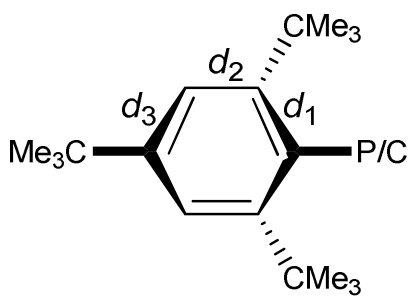

\begin{tabular}{cccc}
\hline & $d_{1} / \AA$ & $d_{2} / \AA$ & $d_{3} / \AA$ \\
\hline $\mathbf{4}$ & $1.432(4)$ & $1.385(5)$ & $1.403(4)$ \\
& $1.422(4)$ & $1.406(5)$ & $1.386(4)$ \\
5: Mes*P & $1.424(7)$ & $1.406(5)$ & $1.386(7)$ \\
& $1.429(7)$ & $1.390(5)$ & $1.393(7)$ \\
5: Mes*C & $1.428(5)$ & $1.379(7)$ & $1.395(7)$ \\
& $1.414(6)$ & $1.401(6)$ & $1.386(7)$ \\
\hline
\end{tabular}

\section{Conclusions}

Steric encumbrance of the 2,4,6-tri-t-butylphenyl (Mes*) group shows remarkable distortion to a boat-type structure indicating preferable characters for stabilization of unstable chemical species. 
According to the X-ray structural determination of chlorophosphine $\mathbf{4}$ and secondary phosphine bearing two Mes* groups 5, the molecular distortion is a result of steric encumbrance around the ipso position. On the other hand, degree of the boat-type distortion depends on the substituent at the ipso aromatic carbon. Thus, steric encumbrance of the Mes* group, which is essential for protecting unstable organophosphorus structures, gives rise to corresponding distortions around the aromatic skeleton, and proper molecular distortion might be a parameter for design of stabilization of reactive intermediates.

\section{Experimental Section}

\section{Crystallographic data for $4^{9}$}

$\mathrm{C}_{27} \mathrm{H}_{42} \mathrm{ClP}: M=433.06$, monoclinic, $P 2{ }_{1} / \mathrm{n}(\# 14), a=8.9814(3), b=17.6217(5), c=16.5341(5)$ $\AA, \beta=93.331(1)^{\circ}, V=2612.4(1) \AA^{3}, Z=4$ (CCDC-667900).

X-ray crystallography for $(2,4,6$-tri-t-butylphenyl $)((2,4,6$-tri-t-butylphenyl)ethynyl $)$ phosphine $(5)^{12}$

Diffractometer: Rigaku RAXIS-IV imaging plate detector, $\mathrm{C}_{38} \mathrm{H}_{59} \mathrm{P}$, colorless prisms $\left(\mathrm{CH}_{2} \mathrm{Cl}_{2}\right), M$ $=546.86$, crystal dimensions $=0.20 \times 0.20 \times 0.15 \mathrm{~mm}^{3}$, tetragonal, space group $P 4_{2} 2_{1} 2(\# 94), a$ $=25.6257(3), b=25.6257(3), c=10.7101(1) \AA, V=7033.1(1) \AA^{3}, Z=8, \lambda=0.7107 \AA, T=133$ $\mathrm{K}, \rho_{\text {calcd }}=1.033 \mathrm{~g} \mathrm{~cm}^{-3}, \mu(\mathrm{MoK} \alpha)=0.100 \mathrm{~mm}^{-1}, 66622$ total reflections $\left(2 \theta_{\max }=51.0^{\circ}\right), 45480$ unique reflections $\left(R_{\text {int }}=0.087\right), R 1=0.0448(I>2 \sigma(I)), R w=0.0496$ (all data), $G O F=0.933$ (366 parameters) (CCDC-818921).

\section{Acknowledgements}

This work was supported in part by Grant-in-Aid for Scientific Research (Nos. 13304049, 14044012, 20750098, and 22350058) from the Ministry of Education, Culture, Sports, Science and Technology, Japan; the Program Research, Center for Interdisciplinary Research, and the Support for Young Researchers, Graduate School of Science, Tohoku University; Casio Science Promotion Foundation; and Nissan Chemical Industries, Ltd. 


\section{References}

1. (a) Yoshifuji, M.; Shima, I.; Inamoto, N.; Hirotsu, K.; Higuchi, T. J. Am. Chem. Soc. 1981, 103, 4587. (b) Yoshifuji, M.; Shima, I.; Inamoto, N.; Hirotsu, K.; Higuchi, T. J. Am. Chem. Soc. 1982, 104, 6167.

2. Dillon, K. B.; Mathey, F.; Nixon, J. F. Phosphorus: The Carbon Copy Wiley: Chichester 1998.

3. (a) Yoshifuji, M.; Ito, S. Top. Curr. Chem. 2003, 223, 67. (b) Yoshifuji, M. J. Chem. Soc. Dalton Trans. 1998, 3343. (c) Fischer, R. C.; Power, P. P. Chem. Rev. 2010, 110, 3877.

4. Yoshifuji, M.; Shima, I.; Inamoto, N. Tetrahedron Lett. 1979, 19, 3963.

5. Yoshifuji, M.; Shima, I.; Inamoto, N.; Aoyama, T. Tetrahedron Lett. 1981, 22, 3057.

6. Yoshifuji, M.; Shima, I.; Inamoto, N.; Hirotsu, K.; Higuchi, T. Angew. Chem. Int. Ed. Engl. 1980, 19, 399.

7. Ito, S.; Yoshifuji, M. Sci. Rep. Tohoku Univ. 1st Ser. 2002, 79, 9.

8. Yoshifuji, M.; Inamoto, N.; Hirotsu, K.; Higuchi, T. J. Chem. Soc., Chem. Commun. 1985, 1109.

9. Ito, S.; Miyake, H.; Yoshifuji, M. Phosphorus, Sulfur, and Silicon 2009, 184, 917.

10. Tsuzuki, S.; Honda, K.; Uchimaru, T.; Mikami, M.; Tanabe, K. J. Am. Chem. Soc. 2000, 122, 3746.

11. Ozawa, F.; Yoshifuji, M. J. Chem. Soc., Dalton Trans. 2006, 4987.

12. Ito, S.; Sugiyama, H.; Yoshifuji, M. Angew. Chem. Int. Ed. 2000, 39, 2781.

13. Cohen, E. A.; McRae, G. A.; Goldwhite, H.; Stefano, S. D.; Beaudet, R. A. Inorg. Chem. 1987, 26, 4000.

14. Beeby, A.; Findlay, K. S.; Goeta, A. E.; Porrès, L.; Rutter, S. R.; Thompson, A. L. Photochem. Photobiol. Sci. 2007, 6, 982.

15. Yoshifuji, M.; Sugiyama, H.; Ito, S. J. Organomet. Chem. 2005, 690, 2515.

16. Ito, S.; Kikuchi, M.; Sugiyama, H.; Yoshifuji, M. J. Organomet. Chem. 2007, 692, 2761.

17. Tobe, Y.; Ueda, K.; Kaneda, T.; Kakiuchi, K.; Odaira, Y.; Kai, Y.; Kasai, N. J. Am. Chem. Soc. 1987, 109, 1136.

18. Hunger, J.; Wolff, C.; Tochtermann, W.; Peters, E.-M.; Peters, K.; von Schering, H. G. Chem. Ber. 1986, 119, 2698. 